\title{
An Overview of Propulsion Concept Studies and Risk Reduction Activities for Robotic Lunar Landers
}

\author{
Huи P. Trinh, George Story, and Chris Burnside \\ NASA Marshall Space Flight Center, Huntsville, Alabama
}

\author{
Al Kudlach \\ Johns Hopkins University Applied Physics Laboratory, Laurel, Maryland
}

\begin{abstract}
$\underline{\text { ABSTRACT }}$
The Robotic Lunar Lander Development Project Office at NASA Marshall Space Flight Center (MSFC), partnering with the Johns Hopkins University Applied Physics Laboratory (APL), is currently studying several lunar surface science mission concepts. These missions will involve spacecraft carrying multiple science instruments with power systems that will allow extended operations on the lunar surface. Initial trade studies of launch vehicle options for these mission concepts indicate that in all cases the spacecraft design will be significantly mass-constrained. For all concepts under review, the propulsion subsystem is the most massive sub-system within the spacecraft. Some mission concepts indicate that the mass fraction for the propulsion sub-system would be greater than $80 \%$ of the entire spacecraft. Therefore selection of an efficiently packaged propulsion concept and light-weight propulsion components are essential for reducing spacecraft mass.
\end{abstract}

In support of designing the lunar lander concepts, the propulsion team at MSFC and APL, with participation from industry, conducted a series of trade studies on propulsion concepts with an emphasis on light-weight and technologically mature components. To minimize development cost and schedule, off-the-shelf components were selected wherever possible, provided that the system mass allocation could be met; where this was not possible, custom components were considered. The results suggested that a high-pressure propulsion system may offer some benefits in weight savings. In parallel with this study effort, the team also began technology risk reduction testing on a high thrust-to-weight descent thruster and a high-pressure regulator. A series of hot-fire tests was completed on the descent thruster in vacuum conditions at NASA White Sands Test Facility (WSTF) in New Mexico in 2009. A hot-fire test series on the attitude control thruster and initial testing on the pressure regulator are planned to be performed during the first half of 2010.

This paper will provide an overview of the concept trade study results along with insight on the risk mitigation activities conducted to date. A limited comparison of results and trends will also be reported, as permitted by the proprietary data restrictions of the participating companies. 


\title{
An Overview of Propulsion Concept Studies and Risk Reduction Activities for Robotic Lunar Landers
}

\author{
Huu P. Trinh ${ }^{1}$, George Story ${ }^{2}$, and Christopher G. Burnside ${ }^{3}$ \\ NASA Marshall Space Flight Center, Huntsville, Alabama 35812, USA \\ Al Kudlach ${ }^{4}$ \\ Johns Hopkins University Applied Physics Laboratory, Laurel, Maryland, 20723-6099, USA
}

\begin{abstract}
In support of designing robotic lunar lander concepts, the propulsion team at NASA Marshall Space Flight Center (MSFC) and the Johns Hopkins University Applied Physics Laboratory (APL), with participation from industry, conducted a series of trade studies on propulsion concepts with an emphasis on light-weight, advanced technology components. The results suggest a high-pressure propulsion system may offer some benefits in weight savings and system packaging. As part of the propulsion system, a solid rocket motor was selected to provide a large impulse to reduce the spacecraft's velocity prior to the lunar descent. In parallel to this study effort, the team also began technology risk reduction testing on a high thrustto-weight descent thruster and a high-pressure regulator. A series of hot-fire tests was completed on the descent thruster in vacuum conditions at NASA White Sands Test Facility (WSTF) in New Mexico in 2009. Preparations for a hot-fire test series on the attitude control thruster at WSTF and for pressure regulator testing are now underway. This paper will provide an overview of the concept trade study results along with insight into the risk mitigation activities conducted to date.
\end{abstract}

\section{Introduction}

$\mathrm{T}$ he Robotic Lunar Lander Development (RLLD) Project Office at MSFC, in partnership with APL, is currently studying lunar surface science mission concepts. Using cutting-edge technology, the RLLD Project plans to create an efficient, light-weight spacecraft to return NASA to the surface of the moon. The new generation of robotic lunar landers, equipped with power systems capable of extended operation, can carry instruments to measure moonquakes, to study resources on the lunar surface including water ice, and to gather information for future human missions. This effort will also provide an opportunity to demonstrate the technology capabilities for future space exploration beyond the moon.

Initial trade studies of launch vehicle options for these mission concepts indicate that in all cases the spacecraft design will be significantly mass-constrained. For all concepts under review, the propulsion subsystem is the most massive subsystem within the spacecraft. Therefore selection of an efficientlypackaged propulsion concept and light-weight propulsion components is essential for reducing spacecraft mass.

\footnotetext{
${ }^{1}$ RLLD Lead Propulsion Engineer, NASA MSFC/ER23

${ }^{2}$ RLLD SRM Propulsion Engineer, NASA MSFC/ER52

${ }^{3}$ RLLD Propulsion Engineer, NASA MSFC/ER23

${ }^{4}$ RLLD Propulsion Engineer, John’s Hopkins University Applied Physics Laboratory
} 
Figure 1: Lunar lander configuration during cruise

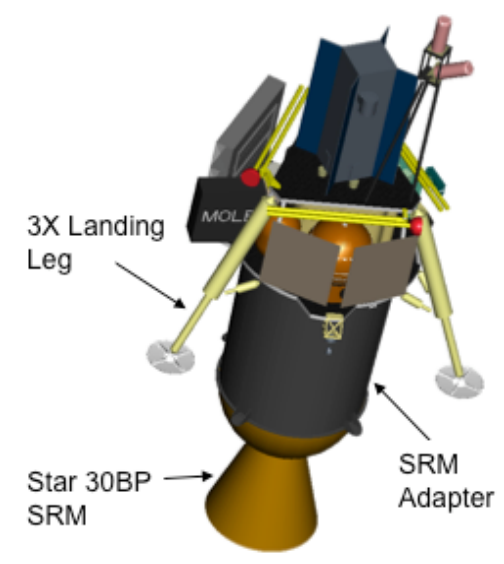

A configuration of the lunar lander during cruising to the moon is shown in Figure 1. On the way to the moon, the spacecraft uses both passive and active thermal control techniques. The helium pressurant tank temperature is maintained with heater power, and the spacecraft will spin to prevent significant temperature differences from developing. There are descent thrusters canted at a small angle outward and clustered around the bottom of the spacecraft. Although the engines primarily provide thrust for the lunar landing, they (as shown in Table 1) are also used during trajectory correction maneuvers for targeting the landing sites, and - if needed - can provide thrust vector control during the SRM braking burn. After solid motor separation, the thrusters will provide the primary control authority during final descent to the surface. During the coast to the moon, the attitude control system (ACS), consisting of small thrusters, will be fired periodically for Trajectory Correction Maneuver (TCM) attitude control, nutation control, and spinup/down.

Table 1: Notional Performance and Configuration for Each Flight Phase of Landers

\begin{tabular}{|c|l|l|l|}
\hline \multirow{2}{*}{ Operation Phases } & \multicolumn{1}{|c|}{ Performing Function } & \multicolumn{1}{|c|}{ Performed by } & \multicolumn{1}{c|}{ Configuration } \\
\hline \multirow{4}{*}{ TCM } & $\begin{array}{c}\text { Trajectory Correction } \\
\text { Maneuver }\end{array}$ & Descent Thrusters & $\begin{array}{l}\text { Lander with SRM attached } \\
\text { at launch separation }\end{array}$ \\
\cline { 2 - 4 } & Targeting for site & Descent Thrusters & Lander with SRM attached \\
\cline { 2 - 5 } & $\begin{array}{l}\text { ACS during cruise: Spin } \\
\text { up/down, TCM control, } \\
\text { nutation damping }\end{array}$ & ACS Thrusters & Lander with SRM attached \\
\hline \multirow{3}{*}{ SRM Burn } & Braking Burn & SRM & Lander with SRM attached \\
\cline { 2 - 5 } & SRM ACS control & Descent Thrusters & Lander with SRM attached \\
\hline \multirow{3}{*}{ Lunar Descent } & Landing ACS control & ACS Thrusters & Lander after SRM release \\
\cline { 2 - 4 } & Landing & Descent Thrusters & Lander after SRM release \\
\hline
\end{tabular}

To provide a framework for the risk mitigation activities, a notional baseline concept was laid out as a point of departure for the design; the system schematic is shown in Figure 2. Multiple 100-lbf thrust (vacuum)-class engines are used for the lunar descent, while small 5-lbf thrust (vacuum)-class thrusters are for the attitude control system. Because of constraints on the propulsion system mass, high thrust-to-weight engines and a high-pressure helium pressurization system were selected for the notional propulsion system. 
Initial research identified the Missile Defense Agency (MDA) propulsion technology as being of particular interest, since the MDA successfully uses such high-pressure and compact systems for its applications. Unfortunately, the available high thrust-to-weight thrusters are currently only qualified for very short duration use. In addition to the high performance thrusters, the inclusion of a 10,000 psi pressurization system could offer mass savings when compared with conventional helium systems. Typical NASA spacecraft operate below 6,000 psi. By increasing the pressure to 10,000 psi the pressurization system size and mass may decrease. Since these high-pressure components and tanks have not previously been used in NASA missions, there are some technical risks in selecting them for spacecraft applications.

Spacecraft mass and power constraints mean that it is undesirable to actively heat the propellant tanks after launch. Thermal analysis shows that, with unheated tanks, the propellant temperatures will fall significantly during the course of the mission. To prevent liquid from freezing, the bipropellant combination of monomethyl hydrazine (MMH) fuel and a 75\% nitrogen tetroxide / 25\% nitric oxide (MON-25) oxidizer has been studied. Both MMH and MON-25 have similar freezing temperatures, and both are below $-50^{\circ}$ Celsius (-58F). [By comparison, MON-3 (which contains only $3 \%$ nitric oxide) freezes at about $-15^{\circ}$ Celsius (5F).] Estimates show that if the propellant tanks are insulated adequately, and are warmed to $45^{\circ}$ Celsius (113F) prior to launch, then at the end of the mission both liquids would still be safely above their respective freezing points. This approach requires no active heating for the tanks after launch.

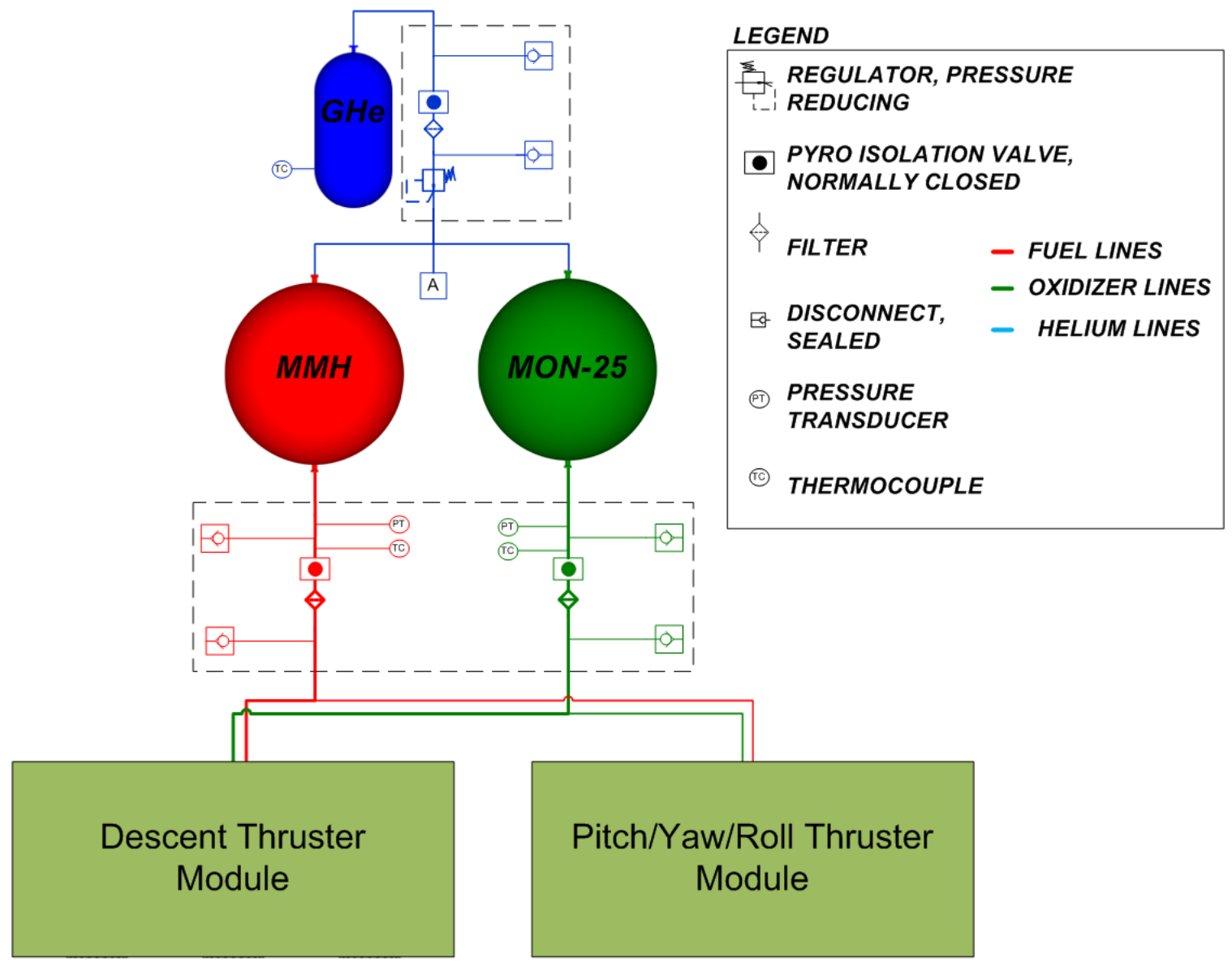

Figure 2: Schematic of Notional Propulsion System Design for the Lunar Lander

Spacecraft mass constraints also dictate the use of some custom components and/or components not yet qualified for the lunar mission. As part of the preliminary design exercise, metal diaphragm tanks were selected to ensure that only gas-free propellant is expelled and also to prevent liquid slosh and center of mass movement. The metal diaphragms being considered are compatible with the MON-25 oxidizer. 
In order to mitigate propulsion development risks and seek ways to optimize the system design, the propulsion team along with the RLLD system engineering team has identified risk reduction activities. These activities include: 1) conducting propulsion concept study; 2) testing high thrust-to-weight thrusters; 3) testing high-pressure regulator; 4) establishing an initial design for an SRM. The following pages report the progress of these risk reduction tasks and describe the process that was implemented to study alternative designs.

\section{Progress on Propulsion Risk Reduction Tasks}

\section{A. Propulsion Concept Studies}

A propulsion concept study ${ }^{1}$, with an assumed Advanced Radioisotope Sterling Generator (ASRG) for spacecraft and lander power throughout the mission, was conducted between May and September 2009. The objective of this study was to develop and evaluate various design concepts applicable to RLLD power and mass-constrained lunar mission. Both cutting-edge missile defense technology and conventional propulsion components were considered. To minimize development cost and schedule, off-the-shelf components were selected wherever possible, provided that the system mass allocation could be met; where this was not possible, custom components were considered.

Several domestic propulsion system companies participated, each conducting independent system design studies under the same set of mission objectives. The notional baseline of the propulsion system described in the previous section was used as a point of departure. Each company performed an independent study and trade of available traditional NASA-used, commercial-of-the-shelf (COTS) components and incorporated elements from MDA systems into the design. The final concepts from the companies validated the design approach used by the RLLD team in the baseline propulsion system design. Some details of the propulsion systems studies are described below.

The propulsion studies were conducted in two phases, the first of which was intended to provide a preliminary assessment of a wide range of design options and the second to provide a more detailed evaluation of the most promising concepts. In general, the propulsion components selected either had been flight qualified already or were assessed to have a fairly high Technology Readiness Level (TRL) typically 6 or above. As much as practical, the various design solutions were studied parametrically to allow a degree of optimization.

During the first study phase a range of different propulsion system design concepts were identified, each based on a particular set of propellants, thrusters and operating pressures. Various propellant combinations were initially considered, (monopropellant, 'green' and bipropellant) but most were eliminated from the trade space due to low TRL numbers or engineering difficulties foreseen due to schedule and development timeline. A range of descent and attitude control thrusters was also considered including conventional, low-pressure engines and high-pressure units baselined in MDA-heritage applications.

Concept analysis started with the mission delta- $\mathrm{V}$, spacecraft volume, and cost/budget constraints and produced a viable propellant budget to meet the goal of the mission. Major system components (pressurant tanks, propellant tanks, regulators, and thrusters were identified which could meet the performance requirements. The mission performance was analyzed and the final dry mass of the lander was derived. The dry mass included both the useful payload and the non-propulsive dry mass of the vehicle.

In all cases, the results from the first phase showed that hypergolic propellant combinations were the best candidates. The preferred design solutions naturally fell into two categories. The first used the MMH/MON-3 propellant combination in conjunction with COTS propulsion hardware with the system operating at conventional pressures. The second category of design solutions operated at higher tank pressures, with non-COTS components, and used the MMH/MON-25 propellant combination with high pressure thrusters.

From the results of the first study phase, the two most promising design solutions were selected for additional evaluation: one from the high-pressure category and one from the COTS category. The first of these was referred to as the Baseline Option and the second as the Alternate Option. These two concepts were then subjected to a more detailed design definition and performance analysis during the second phase of activities. 
Typical Baseline Option design solutions consisted of a composite overwrap pressure vessel (COPV) pressurant tank, with initial pressure in the 4,500-10,000 psia range, feeding a pressure regulator with an outlet setting in the 400-850 psia range. The pressurant and propellant tank pressures varied between concepts; in general it appears that the higher pressure options are not favored because the increased tank mass tends to negate any performance improvements. Various propellant tank options were studied, the vast majority using some type of positive displacement propellant management system (usually a metal diaphragm) to ensure gas-free liquid expulsion. In most cases, all of the tanks and also the pressure regulator were new components.

Typical Alternate Option design solutions used either a metal or a COPV pressurant tank with helium storage at 3,000-4,000 psia. Helium pressure is regulated down to the 250-450 psia range and then fed into the propellant tanks. A variety of propellant tank options were studied, including metal diaphragm designs, elastomeric diaphragms designs, and designs incorporating surface tension propellant management devices. In some cases the elastomeric diaphragms were proposed only for use with $\mathrm{MMH}$, but in a small number of cases, use with MON was argued on the basis of the short operational life of the propulsion system (approximately one week of exposure), which would minimize exposure time. In all cases the Alternate Option design studies identified COTS descent engines and attitude control thrusters, which have some flight heritage. In most cases the descent engines require some reduction in nozzle length for reasons of packaging and ground clearance (after landing).

The study results showed that the Baseline Options outperform the Alternate Options but require components with significantly less flight-heritage and with more development and testing efforts required. However, comparison of results from within the Baseline category shows that performance does not necessarily maximize with pressure. Additional details of risk-reduction testing on selected components are outlined below.

\section{B. High Thrust-to-Weight Thruster Tests}

As stated previously, the high thrust-to-weight thrusters are selected for a notional propulsion design baseline. Due to their small engine envelopes, they are suitable for a highly compact spacecraft. For certain flight missions, the propulsion system using these thrusters has a lower mass than the counterpart system with conventional thrusters. However, these thrusters have not been qualified for the long durations typical of space missions, although they have flown with short duration flights under MDA programs.

The RLLD propulsion team at MSFC, with support from Pratt \& Whitney Rocketdyne (PWR), has been evaluating the use of missile-heritage, miniaturized thruster technologies. Notably, our initial industry survey indicated that PWR has matured thruster hardware available for this risk reduction task. Furthermore, PWR thrusters have been tested with MMH/MON-25 propellant system, which is relevant to our design baseline. The intent of this risk reduction effort is to assess the thruster capability for long duration burns and to evaluate the performance and combustion behaviors with operation excursions through hot-fire tests in vacuum conditions.

The first part of this risk reduction effort was to test a 100-lbf thrust-class thruster, which has been used for Divert and Attitude Control System (DACS) under MDA programs. MSFC and PWR completed this hot-fire test series with MMH/MON-25 in Test Cell 406 at NASA White Sands Test facility (WSTF) in New Mexico ${ }^{(2)}$. Figure 3 shows the thruster test setup in the vacuum chamber at WSTF. In this test, the DACS thruster fired under vacuum conditions to simulate operation in the space environment. The test matrix included various engine pulsing durations, the power level, and propellant mixture ratio. The test culminated in a 66-second continuous burn at full power. The test also included a representative mission duty cycle (MDC) profile. The baseline spacecraft mission profile includes several trajectory correction maneuvers during the cruise phase, nutation control burns to maintain spacecraft orientation, and a terminal descent burn on approach to the lunar surface. This profile spanned 995 seconds and included pulses, coasts, and steady-state burns. The test program fully accomplished its objectives, including evaluation of combustion stability, engine efficiency, and the ability of the thruster to perform the MDC and a long duration steady state burn at full power. 


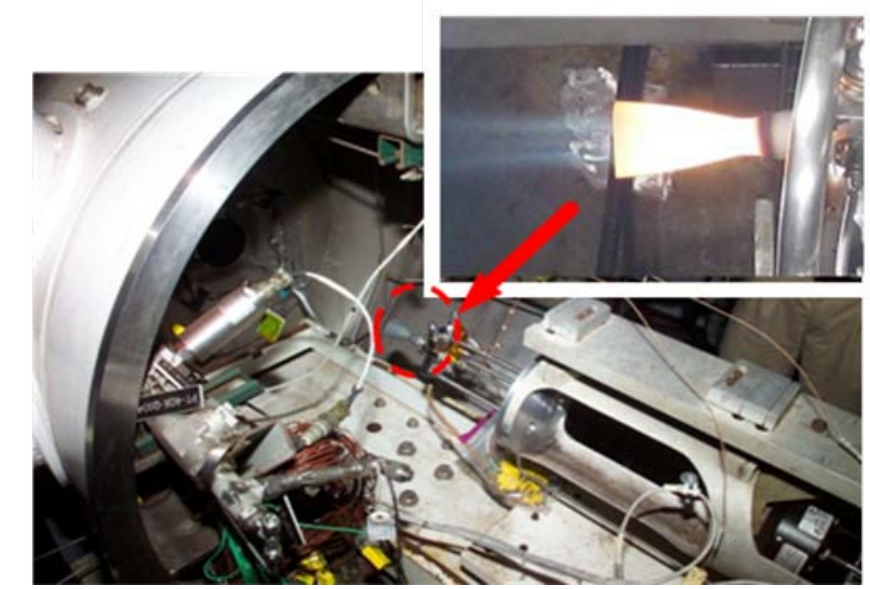

Figure 3: 100-lbf DACS thruster test in Vacuum Chamber at WSTF

A 5-lbf thrust-class thruster will be tested in the second part of this risk reduction effort. The pictorial layout of the thruster along with the mount hardware is shown in figure 4 . The objective for this test series is similar to the one for the 100-lbf thruster with an additional emphasis on the thruster heating due to the long duration MDC and MMH/MON-25 combustion.

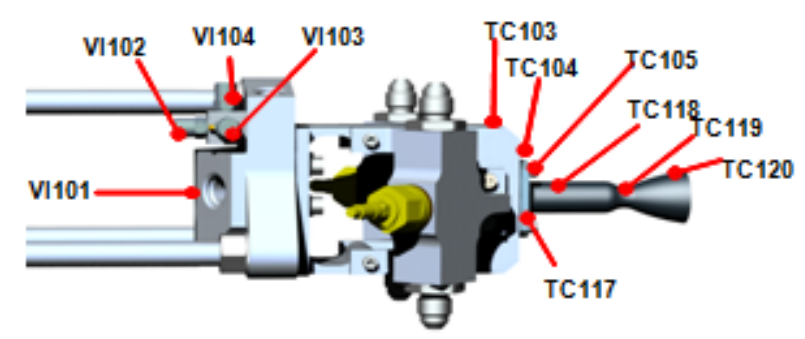

Figure 4: 5-lbf thrust-class thruster with test stand mounting and instrumentation locations (TC: Thermocouples, VI: Accelerometers)

Preparation for the ACS thruster test is currently underway. The test will be conducted in Test Cell 406 at WSTF in 2010. Similar to the 100-lbf thruster test, the test matrix will also contain a series of hot fires to evaluate combustion performance along with a mission-representative duty cycle. All tests will be performed in vacuum conditions.

\section{Pressure Regulator tests}

The regulator test activity is part of the propulsion system risk reduction activities. The test activity has three (3) objectives to evaluate the regulator operation during the spacecraft mission profile. The first is to familiarize the propulsion team with 10,000 psi helium pressurization system technologies, which are not traditionally used on NASA spacecraft. The second objective is to characterize the ability of the regulator to maintain the design outlet pressure within the design tolerance band during all flow conditions. The third objective is the assessment of the rapid change in helium temperature. During the lunar terminal descent, the pressurization system expends approximately $65 \%$ of the helium in a short period of time, resulting in near isentropic expansion gas temperatures; hence, the helium temperature drops rapidly during the operation

The regulator has heritage in MDA applications. As shown in figure 5, the regulator being tested is a Cobham (formerly Carleton Technologies) regulator. This regulator was chosen because of the similarity of the heritage mission to the flow requirements of the RLLD spacecraft mission. The data and analysis generated from this test activity will provide a road map to determining requirements for a potential flight system regulator. 

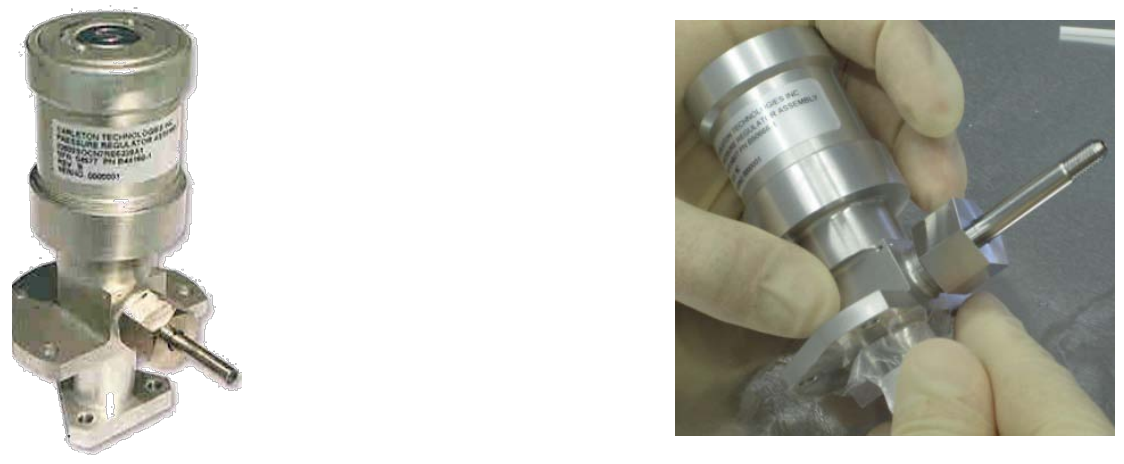

Figure 5: Carleton Regulator unit under test by MSFC

The test activity is being conducted at the MSFC Component Development Area (CDA). The CDA provides data acquisition, 10,000-psia helium supply, and engineering support for the test activity. A blast-rated bunker houses the test fixture. The test fixture consists of two (2) 7.5-liter helium Composite Overwrap Pressure Vessels (COPV's) located upstream of a helium isolation valve. The regulator test article is located downstream of the isolation valve and controls pressure in two (2) water-filled COPV's, simulating propellant tanks. Two (2) valves are used to control water flow from the system. The valves can perform a simulated mission duty cycle and matches the total flow rate of propellants, as adjusted to the density of water. A burst disk is installed during slam-start testing. The burst disk slam-start simulates the operation of a pyro valve as the expected isolation strategy for the flight system. Figure 6 shows the test facility at the completion of build-up prior to the start of testing.

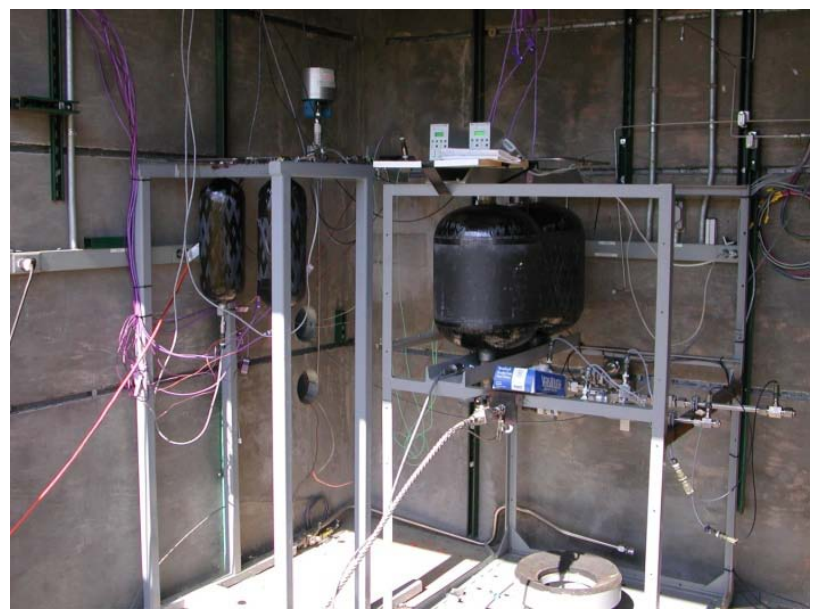

Figure 6: Regulator Test Facility at MSFC

The test activity is focused on determining the performance of the regulator during various phases of the mission. Estimation of the internal leak rate during lock-up conditions is performed between various tests to determine the health of the regulator. A set of lock-up tests at various pressures is conducted to determine the capability of the regulator to maintain tank pressure below a desired pressure. The regulator test facility also provides the capability to perform a simulated MDC similar to what the flight system will perform during various phases of the mission. The MDC was generated by the Guidance, Navigation \& Control (GN\&C) team responsible for flight profile design.

The test matrix is designed to maximize the amount of test data available while progressively moving to higher risk test activities. Initial testing will focus on determining regulator performance during gas blow down and water expulsion testing. As the test team becomes more familiar with the hardware and test setup, testing will progress to the simulated MDC and culminate with the slam-start test. Following the completion of the slam-start test, the health of the regulator will be verified by repeating some of the 
previous tests. A comparison of the regulator response and outlet pressure verifies the health of the regulator.

At the time of writing this paper, the test facility is fully assembled, and initial checks of hardware have been completed. Modifications to plumbing are in-work to reduce excessive slam-start pressurization rates, potentially generated during normal test operation. During the development of the test rig, the pressurization rate on the regulator inlet has become a point of interest in the risk reduction activity. The slam-start event may develop excessive pressurization rates. Plumbing modifications to introduce a helium bleed downstream of the isolation valve have been added to the test rig with the goal of mitigating excessive slam-start pressurization rates. The regulator testing activity is scheduled to be completed by late 2010.

\section{Initial study of SRM design}

During the mission concept studies, propulsion trade studies for the braking burn stage were conducted. Due to the high total impulse requirement and its high propellant mass ratio, a solid rocket motor has been selected to produce the thrust during the "braking burn" to reduce the lander velocity relative to the lunar surface prior to its terminal descent phase. After the solid motor fires, the motor is jettisoned from the spacecraft, and the liquid propulsion system is used for the soft landing.

For a precision landing, the knowledge of the exact SRM burn time is desirable; otherwise, considerable reserved liquid propellants are required to compensate for the unknown burn time. However, the exact burn time may be difficult to estimate due to its dependency of the propellant mean bulk temperature (PMBT) during the operation and the variation of propellant burn rate from one motor to another. Thermal modeling of the spacecraft is being done to provide ranges of PMBT.

For our mission, detailed SRM total impulse requirements are needed to provide the motor sizing. This may require changes in propellant mass (off or up loaded), the motor case dimension and mass, and other motor components from a baseline motor selection. Hence, two contracts with solid manufacturers were established early in the mission iterations to help size motors and provide information for the mission concept design. ATK has a sizable history with space solid rocket motors and commercial-off-the-shelf (COTS) designs and has a catalog available for easy reference. They provided detailed information on interface issues and other questions- Aerojet participated in the preliminary motor sizing for the requirements at the time, based on propellants, case, and nozzle materials currently in production for other systems at Aerojet. As the program progressed and the mission iterations continued, we extended contracts with ATK to get detailed information on the COTS STAR motors.

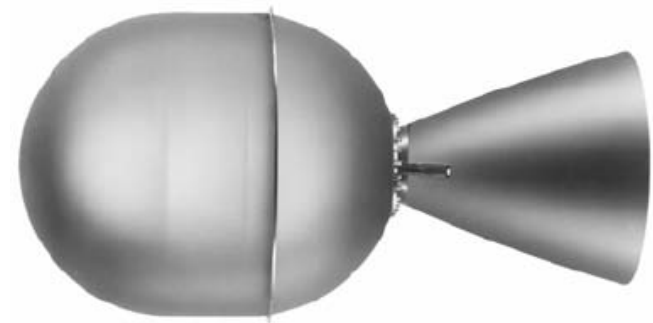

STAR 30BP

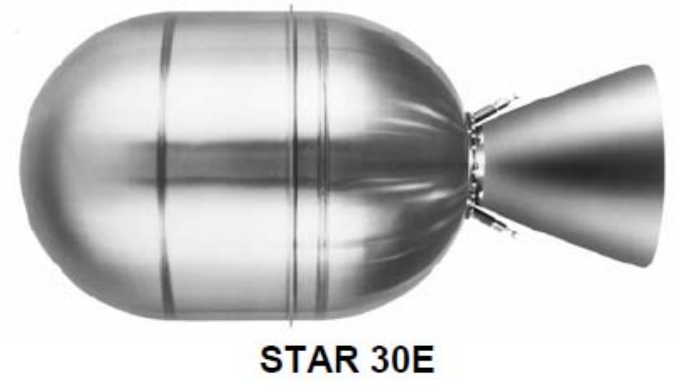

STAR 30E

Figure 7: ATK STAR 30 Family of Solid Rocket Motors

Detailed drawings from COTS ATK motors were provided to the RLLD team for the mission concept studies. The initial concept designs suggest the need for an SRM class equivalent to ATK STAR30 motors. The STAR Motors have been developed for upper stage and space motor applications, with successful flights starting in the 1980s. The data for STAR 30 BP and STAR 30 E provided by ATK was then used to run the industry standard Solid Propulsion Prediction Program (SPP) ${ }^{[4]}$ for the STAR 30 BP and STAR 30 E motors. Analysis was conducted to predict the thrust and then correlated to static motor test data. The SPP models, with some burn rate hump factor modifications, were good matches to the test motor traces. See Figure 8 and Figure 9 for details. 


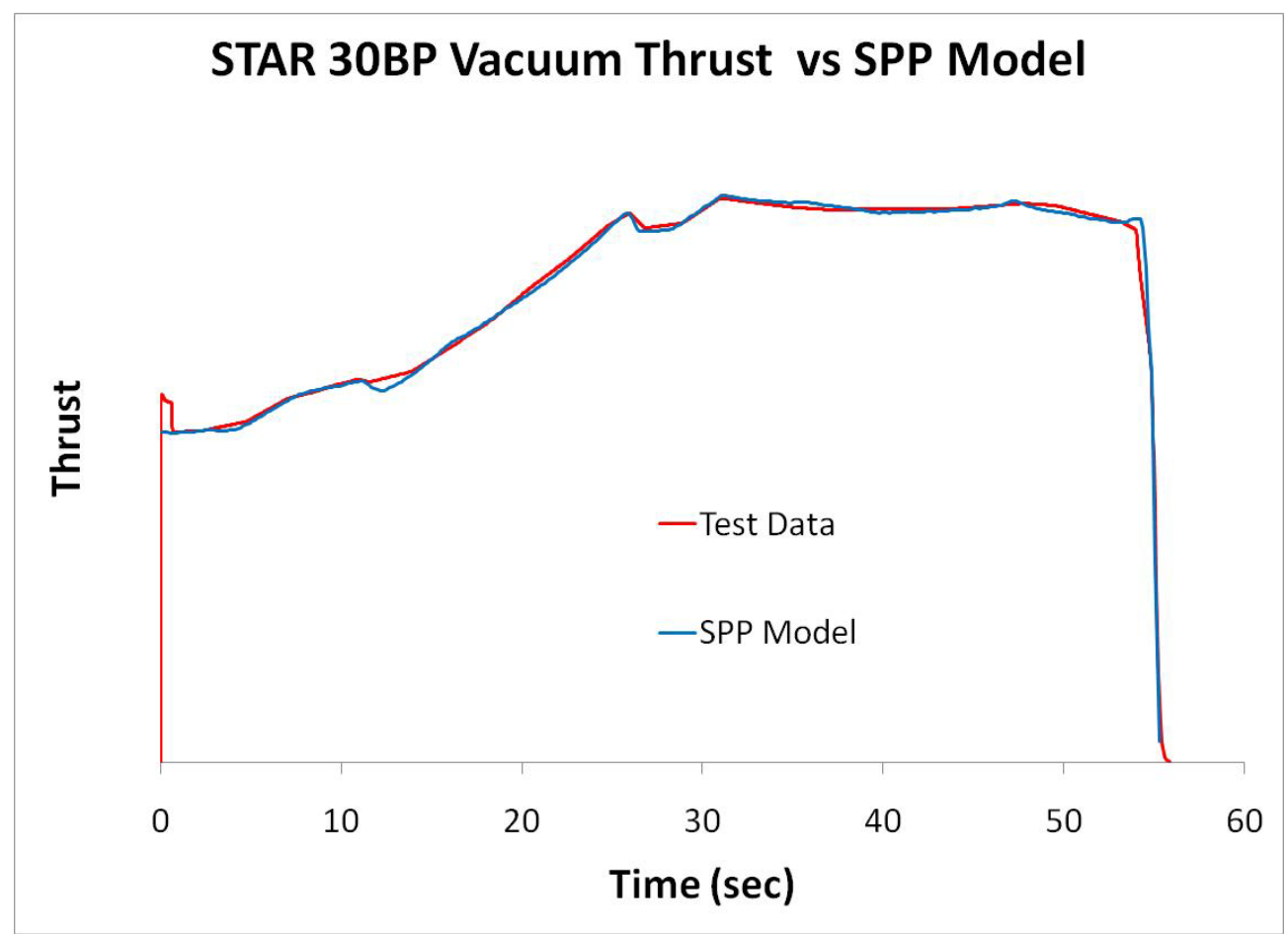

Figure 8: STAR 30BP Vacuum Thrust vs. SPP Model ${ }^{[5]}$

During the course of the mission concept, the RLLD engineering team also conducted the preliminary insulation design to protect the SRM from the extreme-hazard space temperature environment. The results indicate that the solid motor would remain within the PMBT ranges of the motor specification; however, there would be temperature stratification axially and radially in the motor. The SPP model PMBT was also modified to evaluate the thermal variations. SPP can handle variations in PMBT as long as the distribution is symmetric throughout the motor. The temperature stratifications were within the upper and lower temperature specification limits of the motor, and the resultant thrust traces were between the thrust at those extreme motor conditions. Figure 8shows a comparison with uniform PMBT conditions; however, the motor is qualified for a larger PMBT range from 40 to 90 degrees $\mathrm{F}^{[4]}$. 


\section{STAR 30 BP Pressure Effects from Axial and Radial Temperature Gradients vs uniform PMBT}

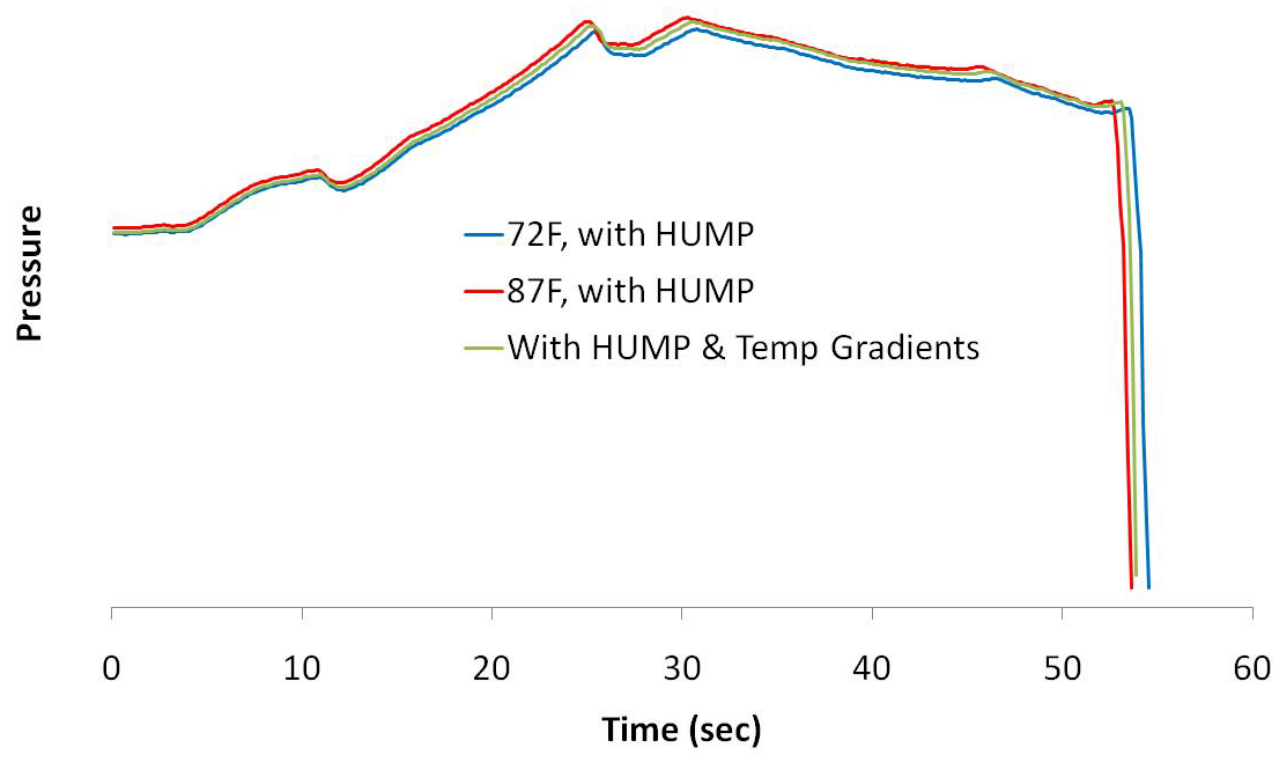

Figure 9: STAR 30BP Pressure Effects from Axial and Radial Temperature Gradients vs. Uniform PMBT ${ }^{[6]}$

In the latest iteration of the mission concept, the landing is potentially in a specific crater at the lunar pole. This scenario requires a larger total impulse and nozzle vectoring due to the large payload and precision landing. These requirements lead to the need for a larger motor, a STAR 48BV class motor size, with a vector-able nozzle. The "thrust vs. time" precision required will be higher for this mission. Temperature variations and motor-to-motor propellant burn rate variations still need to be evaluated for this mission. Current plans for the latest design iteration include getting detailed motor drawings from ATK for the STAR 48BV motor, generating SPP models, and evaluating the temperature variation from the flight.

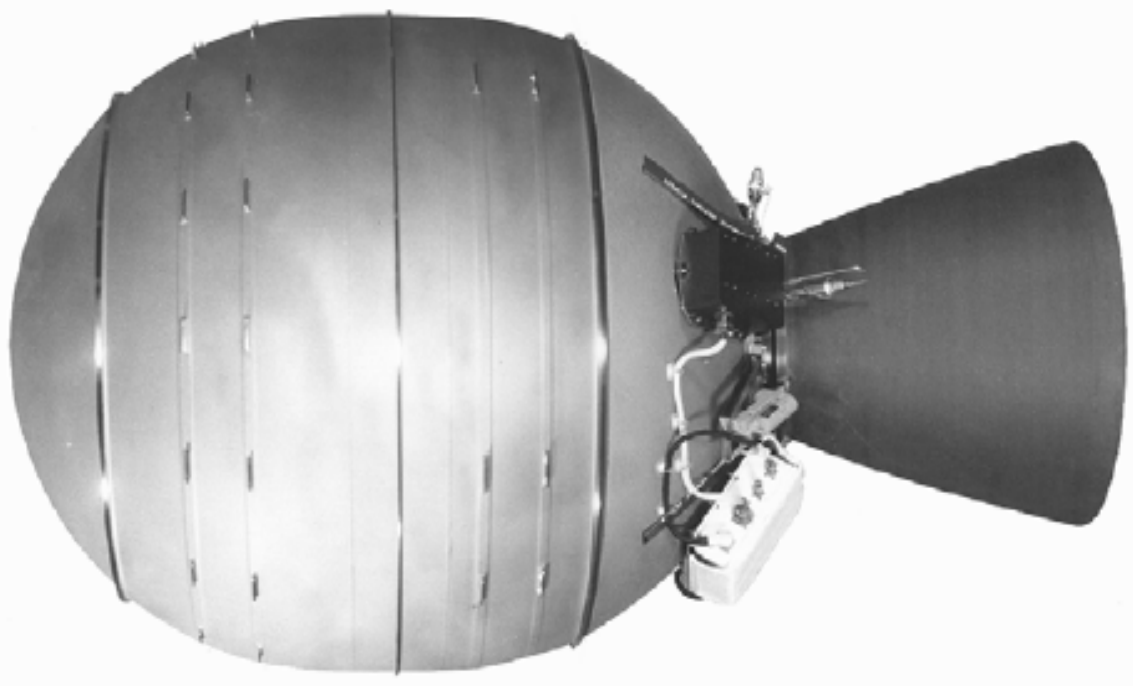

Figure 10: ATK STAR 48V Solid Rocket Motor 


\section{Conclusion}

Since the risk mitigation activities started, considerable progress has been made on risk reduction tasks for the propulsion development under the RLLD project. Four propulsion companies; Aerojet, AMPAC ISP, Orion Propulsion, and Pratt \& Whitney-Rocketdyne, completed short-term propulsion concept studies. Although there were some variations in the component selections and operation conditions among their concept designs, they produced similar results regarding the propulsion system mass, technology readiness assessment, and propulsion development schedule. These results also independently verified the notional propulsion concept formulated by the RLLD team. The companies also provided similar evaluations between high-pressure systems and conventional systems. The design maturity of propulsion system based on the MDA heritage varies among the companies due to the fact that the data and information availability for such systems are limited. Overall, the studies have enriched the data base for future propulsion trade study.

For the thruster risk reduction task, the team achieved the objective of completing an assessment of the 100-lbf thrust-class by hot-fire testing in relevant vacuum conditions. The test data are valuable for future trades and design activities. The team also identified hardware enhancements and developed recommended forward plans to advance high thrust-to-weight thruster technology. Preparations for ACS thruster testing are in progress at this time. This testing is expected to produce highly valuable data for the assessment of high-pressure systems for NASA spacecraft applications.

Regarding the pressure regulator test, the propulsion team has made good progress on the test facility build up. The test preparation is well underway. Because this is the first time for NASA to test the flight-ready regulator hardware at 10,000 psia, considerable care has been invested in the test setup and test procedure. The propulsion team expects to draw valuable data and lessons learned from these test activities.

Finally, the propulsion team has provided relevant SRM data to other teams, such as GN\&C and mechanical and structure, within the RLLD project to mature the lander concept design. Two industry partners, Aerojet and ATK, have engaged in SRM sizing for several mission concepts. Detailed SRM performance data (burn time, thrust profile, environment dependency, etc.) and hardware interfaces (SRM adaptor, hot-gas impingement, antenna mount, etc.) have been incorporated in the lander design and mission analysis. Maintaining technical communication with our industry counterparts throughout the lander design progress is important to the project's success.

In summary, the on-going work has provided valuable data and information to mitigate technical risks in the propulsion development. Clearly, the outcome of the risk reduction efforts will considerably buy down cost and schedule for the development phase of the program.

\section{Acknowledgments}

The authors would like to thank all of the technical teams from Aerojet, AMPAC ISP, ATK, Dynetics (formerly Orion Propulsion), and Pratt \& Whitney-Rocketdyne for their contributions to the risk reduction activities. Technical guidance by the RLLD team, especially Danny Harris, during the initial formulation of the study is appreciated. The authors also want to extend their appreciation to Wayne Dellinger and Jim Kaidy of the GN\&C team for their technical inputs. Finally, these studies could not be conducted without the resource support from the Robotic Lunar Lander Development Project management team, including Julie Bassler and Monica Hammond. Author C.G. Burnside would also like to thank Kevin Pedersen of the NASA Spacecraft \& Auxiliary Propulsion branch for his tireless efforts in providing guidance, expertise, and resources during the development of the regulator test activity.

\section{References}

1. Trinh, H., and et al.,"Light-Weight Propulsion System Concept Study for Robotic Lunar Landers", JANNAF paper, 57th JANNAF Propulsion Meeting, $7^{\text {th }}$ Modeling and Simulation $/ 5^{\text {th }}$ Liquid Propulsion / $4^{\text {th }}$ Spacecraft Propulsion Joint Subcommittee, May 2010.

2. Brown, B. and et. al., "NASA ILN Descent Engine Risk Reduction Tests Data Review,” Presentation charts, Pratt \&Whitney Rocketdyne, Attitude Control Propulsion System, Sept. 2009.

3. ATK Space Propulsion Products Catalog, public release OSR No. 08-S-0259 and OSR No. 08-S-1556, dated 14, May 2008.

4. Dunn, Stuart S., Coats, Douglas E., Software and Engineering Associates, Inc., Carson City, NV; AIAA-1997-3340; AIAA/ASME/SAE/ASEE Joint Propulsion Conference and Exhibit, 33rd, Seattle, WA, July 6-9, 1997, [2] http://www.seainc.com/spp.d.html 
5. Evans, John, Jacobs ESTS Group Product ID: ESTSG-FY09-02341, “International Lunar Network: Motor Ballistics Update”, August 31, 2009

6. Evans, John, Jacobs ESTS Group Product ID: ESTSG-FY10-01443, "Robotic Lunar Lander Development Project: Status of Solid Motor Modeling and Performance Predictions”, April 21, 2010 


\title{
An Overview of Propulsion Concept Studies and Risk Reduction Activities for Robotic Lunar Landers
}

\author{
Huu P. Trinh \\ NASA Marshall Space Flight Center \\ Huntsville, Alabama \\ 30 Aug. - 2 Sept. 2010 \\ AIAA Space 2010 Conference \& Exposition \\ Anaheim, California \\ Co-Authors \\ George Story \\ Chris Burnside \\ Al Kudlach
}




\section{Presentation Content}

Background and Introduction

$\square$ Notional Propulsion Concept

$\square$ Risk reduction development

$\square$ Status summary on

- Propulsion Concept Study

- High thrust-to-weight thruster tests

- High pressure regulator test

- Initial design/sizing of solid rocket motor

$\square$ Conclusions 
$\square$ Robotic Lunar Lander (RLL) Development Project Office at MSFC has conducted lunar mission concept studies.

$\square$ Highly constrained lander mass in order to meet mission requirements.

$\square$ For certain lander configurations, system packaging is also important.

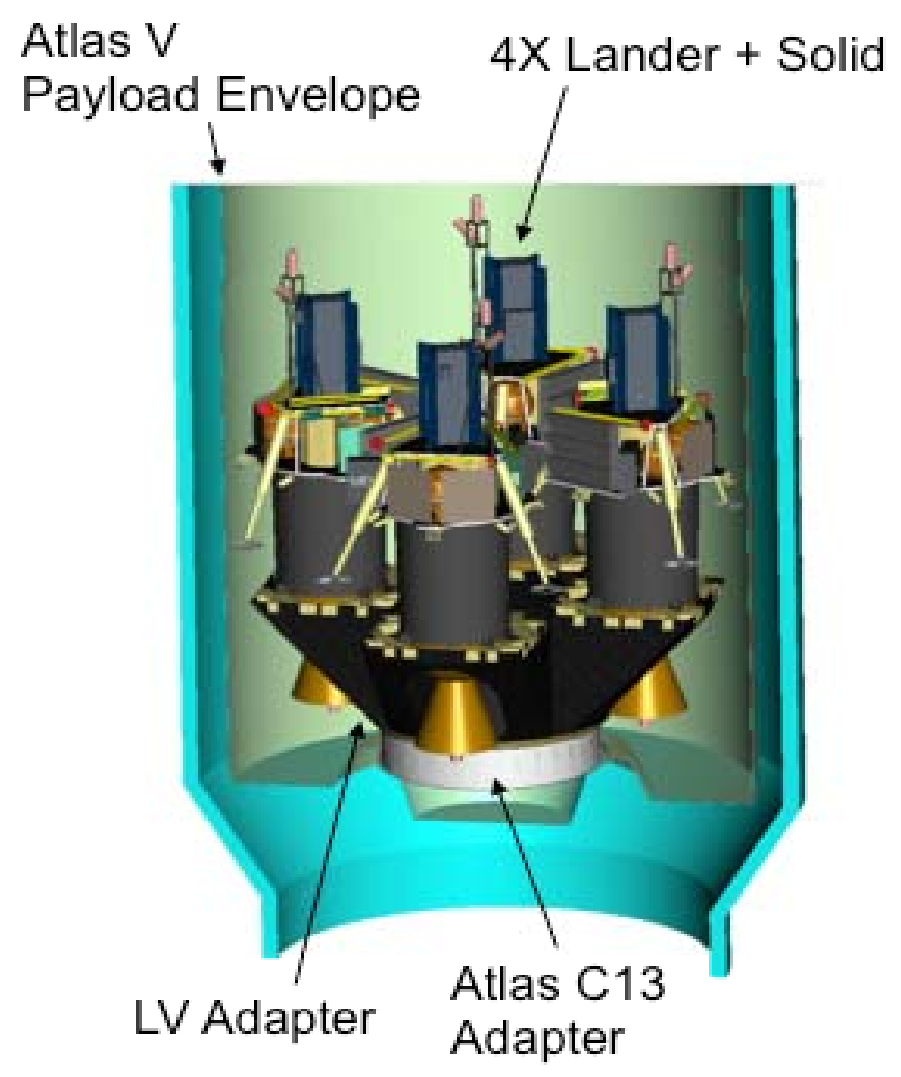

Launch Configuration for Four Landers in an Atlas V 511 Rocket 


\section{Background \& Introduction: - Mission Flow}

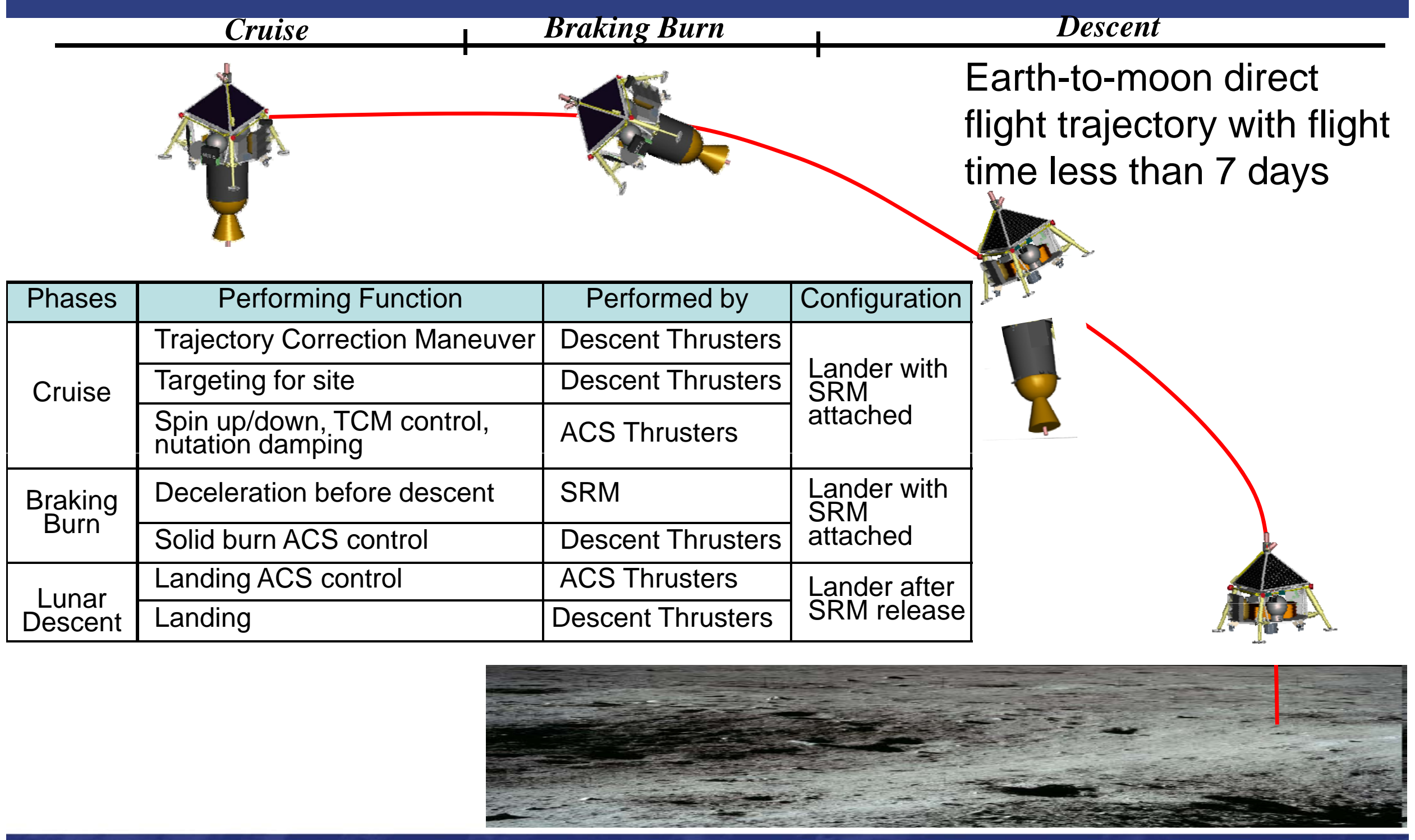


$\square$ Propulsion system, including a SRM for the braking burn, comprises a large share $(>\mathbf{8 0 \%})$ of total lander mass

$\square$ Lightweight propulsion concept has a significant positive impact on the lander design.

$\square$ Only considered propulsion components that are already flight qualified or have a high level of technology maturity in order to minimize development risks, cost and schedule.

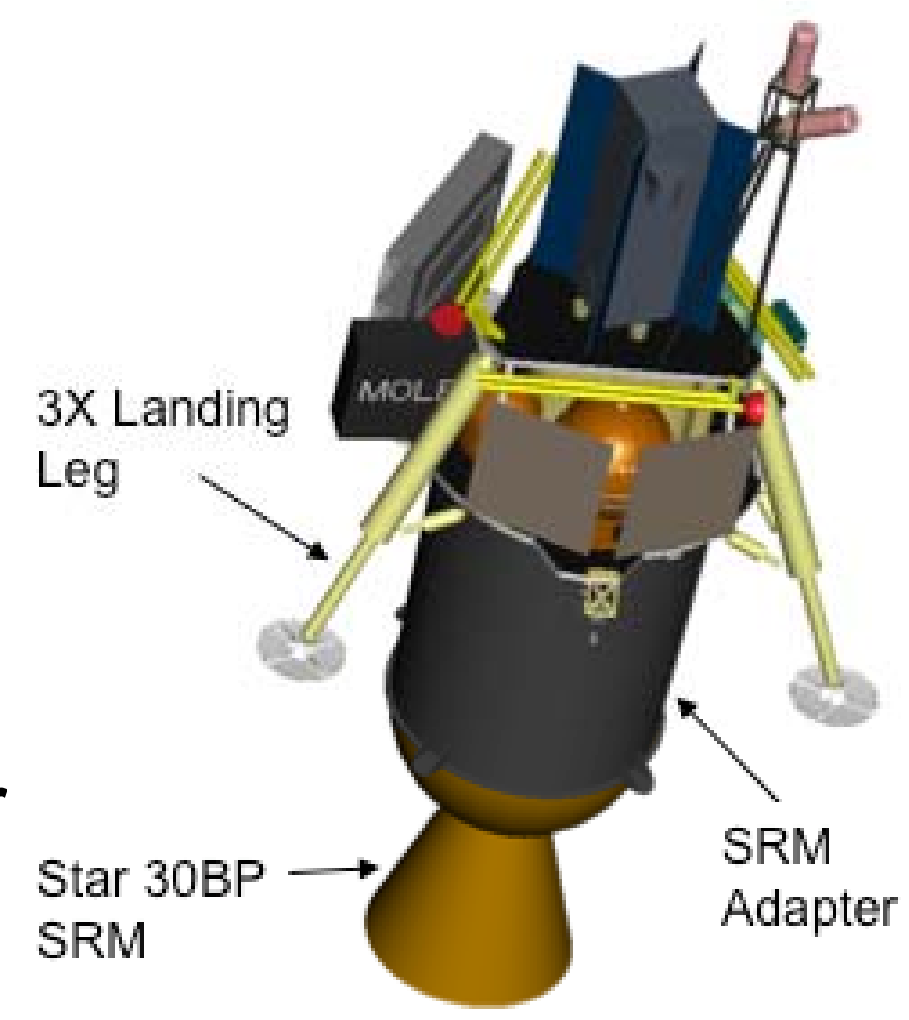

$\square$ Certain components can be customized if justified.

Lunar Lander Configuration During Cruise 


\section{Notional Propulsion System Layout}

$\square$ Pressure-regulated system

$\square$ Single-string architecture with two-fault tolerance on ground operation.

$\square$ Custom tanks based on flight qualified design.

$\square$ MMH/MON-25 propellants for high Isp and low heater power requirement.

$\square$ High pressure system to leverage missile defense heritage technology.
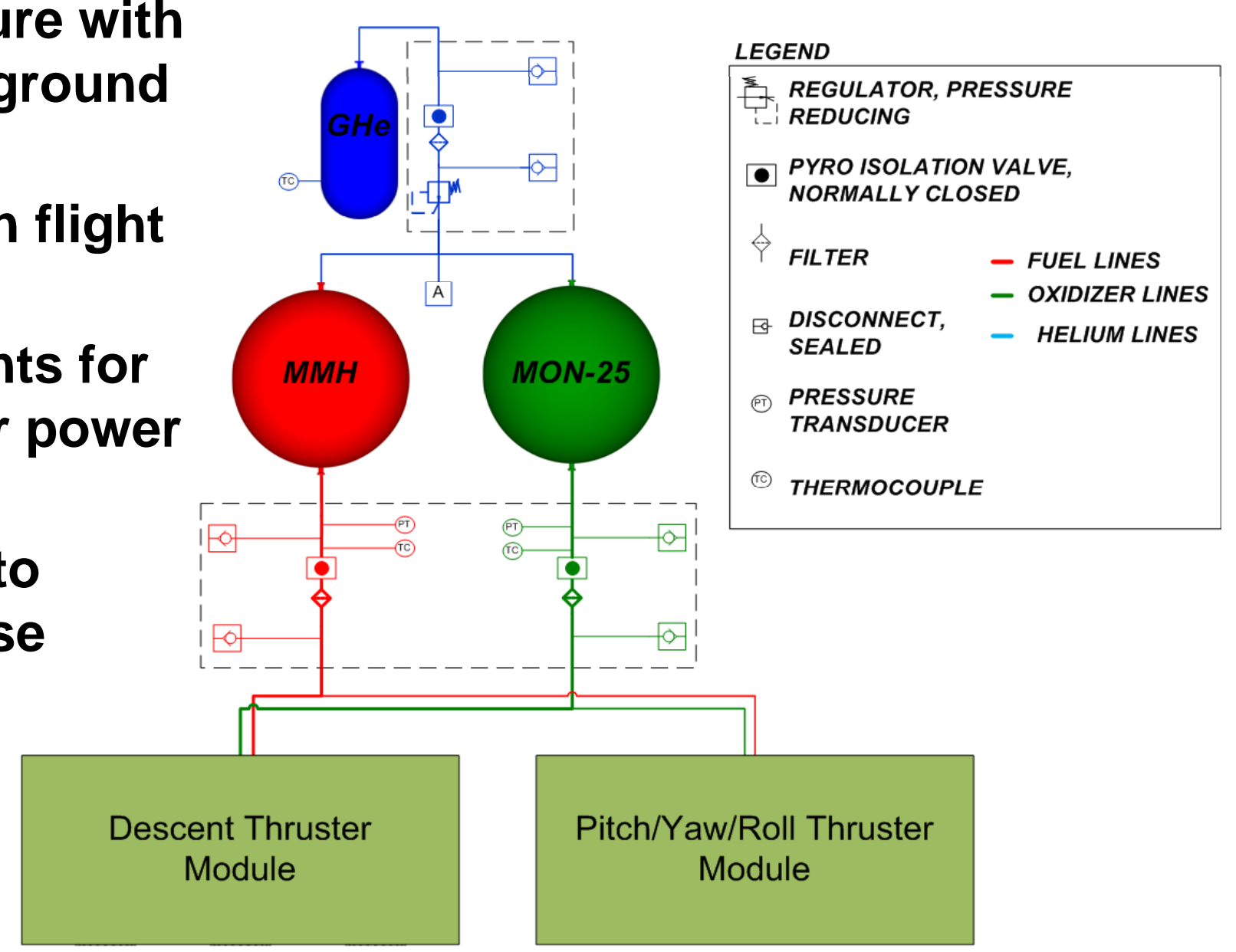


\section{Risks on Propulsion Development}

\section{Four main risk reduction tasks were identified at high risk to the propulsion system development.}

\begin{tabular}{|c|c|c|c|c|c|}
\hline Ref\# & Priority & Candidate Activity & Subsytem & Risk description & $\begin{array}{c}\text { Test } \\
\text { Environment } \\
\end{array}$ \\
\hline 8 & $\begin{array}{c}\text { H } \\
\text { (enabling \& } \\
\text { schedule) }\end{array}$ & 100 Ibf DACS thruster testing & Propulsion & \multirow{2}{*}{$\begin{array}{l}\text { 1) Bum time duration believed to exceed thruster qualification and } \\
\text { previous flight experience; 2) Performance is not thoroughly } \\
\text { understood - establish performance/300 sec ISP; 3) Operation } \\
\text { with MON25/MMH has not been established/verified; 4) } \\
\text { Combustion stability has not been established; 5) Long lead item }\end{array}$} & $\begin{array}{c}\text { External to } \\
\text { Lander Test } \\
\text { Bed }\end{array}$ \\
\hline $\mathbf{C}$ & $\begin{array}{c}\text { 다 } \\
\text { (enabling \& } \\
\text { schedule) }\end{array}$ & 6 Ibf DACS thurster testing & Propulsion & & $\begin{array}{c}\text { External to } \\
\text { Lander Test } \\
\text { Bed }\end{array}$ \\
\hline & $\begin{array}{c}\text { He } \\
\text { Technical \& } \\
\text { Development }\end{array}$ & $\begin{array}{l}\text { Helium pressure regulator } \\
\text { testing }\end{array}$ & Propulsion & $\begin{array}{l}\text { 1) high pressure blow down ratio (10:1). } 10000 \text { psi to } 1000 \text { psi; 2) } \\
\text { rapid change in helium temperature during the descent burn; 3) } \\
\text { arrangement of pyro valve upstream of the regulator/potential pyro } \\
\text { shock causing sudden pressurization of system; (4) Low helium } \\
\text { temperature during blowdown }\end{array}$ & $\begin{array}{c}\text { External to } \\
\text { Lander Test } \\
\text { Bed }\end{array}$ \\
\hline & I & $\begin{array}{l}\text { Propulsion System Concept } \\
\text { Design Study }\end{array}$ & Propulsion & $\begin{array}{l}\text { ILN propulsion concept is based on component performance, } \\
\text { system packaging, operations concept, assumptions that could } \\
\text { prove inaccurate in some cases. Concept design studies } \\
\text { performed by industry experts need to be completed to address } \\
\text { any significant issues that may impact (or improwe) overall } \\
\text { mission scenario }\end{array}$ & Not a test \\
\hline
\end{tabular}




\section{RLL Propulsion Concept Study (1 of 3 )}

\section{Objective:}

\section{Task Overview}

Conduct a short-term propulsion concept study with industry-wide participation to provide:

- Independent assessment of notional baseline design in terms of propulsion mass allocation, component performance/operation conditions

$\square$ Identification and evaluation of alternative/innovative design concepts

\section{Scope of Work:}

Conduct concept trade studies - propulsion architectures, Commercial Off the Shelf (COTS) vs. custom components, propellants - for optimum mass and technology maturity.

$\square$ Develop and evaluate selected propulsion concepts

$\square$ Provide a system layout and identify technical risks, cost, and work schedule associated with the proposed concepts 


\section{RLL Propulsion Concept Study (2 of 3)}

\section{Result Summary}

$\square$ Four companies, Aerojet, AMPAC In-Space Propulsion, Orion Propulsion (recently acquired by Dynetics), and Pratt \& Whitney Rocketdyne, took part in the independent propulsion concept study.

$\square$ Trade study showed more favorable on hypergolic bi-propellants, MMH/MON-25\% of NO, due to high performance, low system mass, and to meet mission requirements.

$\square$ Custom propellant tanks derived from existing flight qualified design.

$\square$ Helium pressurization systems come with two different pressures settings

- 4,000 to 5,000 psia with space flight-proven operation

- 10,000 psia using the missile defense heritage operation 


\section{RLL Propulsion Concept Study (3 of 3)}

\section{Result Summary}

$\square$ Trade study between conventional system vs. high-pressure system was conducted.

- High-pressure systems are derived from missile defense heritage hardware for relatively short flight duration.

o Benefits of high-pressure systems are 1) some savings in mass; 2) efficient system packaging, 3) minimal heater power requirement.

- Conventional propulsion systems are designed based on major components already flight qualified for space applications.

o Benefits of conventional systems are 1) flight-qualified for space application, 2) short development schedule; 3) low development risks.

aAll studies validate the notional design approach, mass estimate and component choices. 


\section{High thrust-to-weight thruster tests (1 of 3 )}

\section{Task Overview}

\section{Background:}

$\square$ Trade study on RLL propulsion shows high thrust-to-weight (HTTW) thrusters offer savings in system mass and efficient system packaging.

$\square$ Leveraging missile defense hardware heritage technology

$\square$ HTTW thrusters have not used in NASA spacecrafts for long flight duration and deep space environments.

$\square$ Two thrust-c lasses are of interested

- 100-Ibf for trajectory correction maneuver, thrust vector correction during the SRM braking burn, and lunar descent

- 5-lbf for attitude control system

\section{Objective:}

$\square$ Access existing thrusters data applicable to RLL

$\square$ Evaluate thrusters for long duration burn, Isp, combustion stability, operation excursions through hot-fire tests

$\square$ Identify hardware modification and/or risks, as necessary 


\section{High thrust-to-weight thruster tests (2 of 3 )}

\section{Status Summary}

$\square$ PWR KEW-4 thruster and KEW-7 are used for this feasibility assessment.

- KEW-4 is a pulsing, 100-lbf thrust-class thruster that has been used for divert and attitude control system (DACS).

- KEW-7 is a 5-lbf thrust class thruster for attitude control system.

$\square$ Completed KEW-4 thruster in vacuum conditions at NASA White Sands Test Facility in New Mexico in September 2009

- Test matrix was composed of operating condition excursions (chamber pressure, mixture ratio) long duration of 66 seconds, and a representative mission duty cycle (MDC) profile.

- Obtained test data to assess the performance, combustion stability, and thermal data on long duration burn.

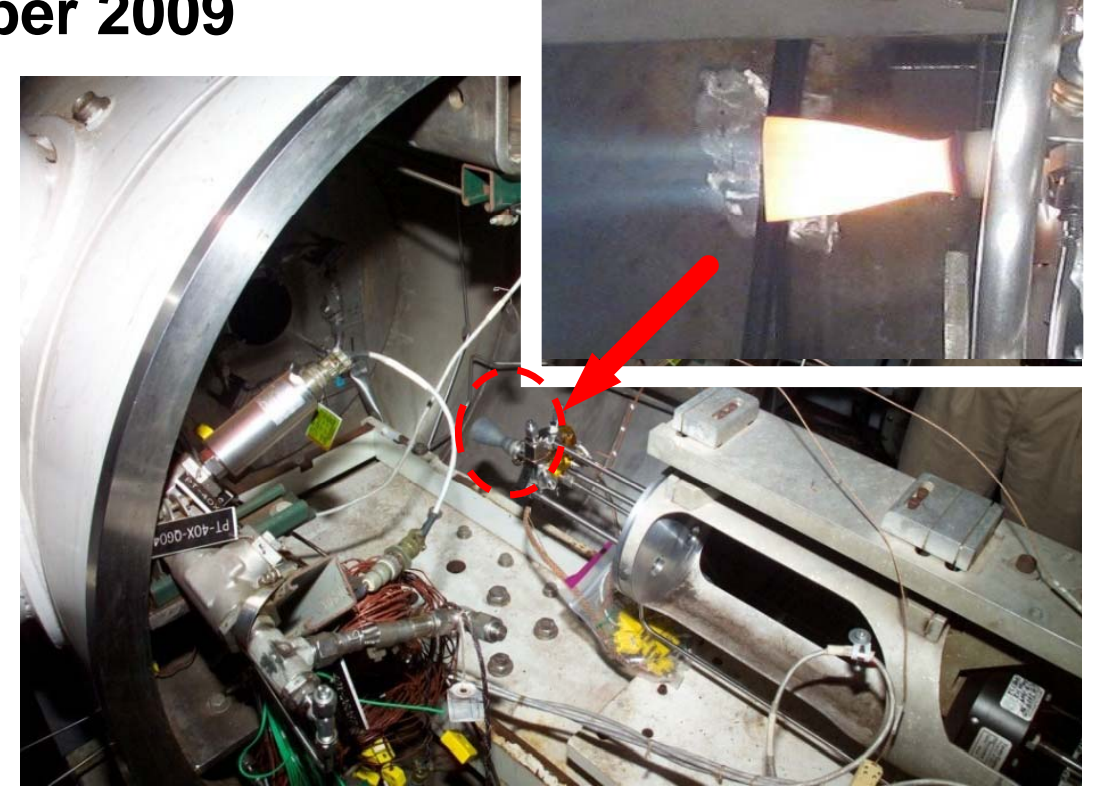

KEW-4 Thruster in vacuum chamber 


\section{High thrust-to-weight thruster tests ( 3 of 3 )}

\section{Status Summary}

$\square$ KEW-7 ACS thruster will be tested in vacuum conditions at WSTF in September 2010.

$\square$ Currently getting ready for the KEW-7 ACS thruster hot-fire test.

- Completed PDR and CDR for test facility setup.

- Verifying measurement systems (thrust, flow, sensors)

$\square$ Test matrix for the ACS thruster will be composed of pulse-width variations, long duration burns, and representative MDC profiles.

$\square$ Test readiness review is scheduled for the week of September 13.

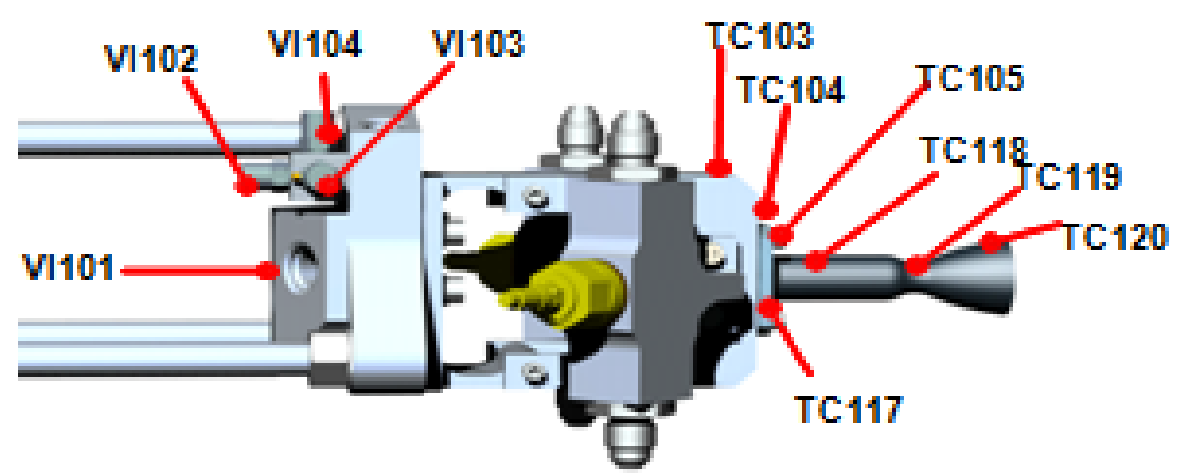

ACS thruster with test stand mounting and instrumentation locations 


\section{High pressure regulator test (1 of 2 )}

\section{Background:}

\section{Task Overview}

$\square$ RLL Propulsion system is baselined with a helium pressurization system at 10,000 psia for system package and savings in mass.

$\square$ High pressure regulator is used in missile defense, but NASA has not traditionally used high-pressure propulsion system for spacecraft applications

\section{Objective:}

Assessment high-pressure regulator for RLL application

$\square$ Evaluate performance under RLL operating conditions.

$\square$ Characterize the ability to maintain the outlet pressure under design tolerance band.

$\square$ Provide a road map to determining requirements for a potential flight system regulator.

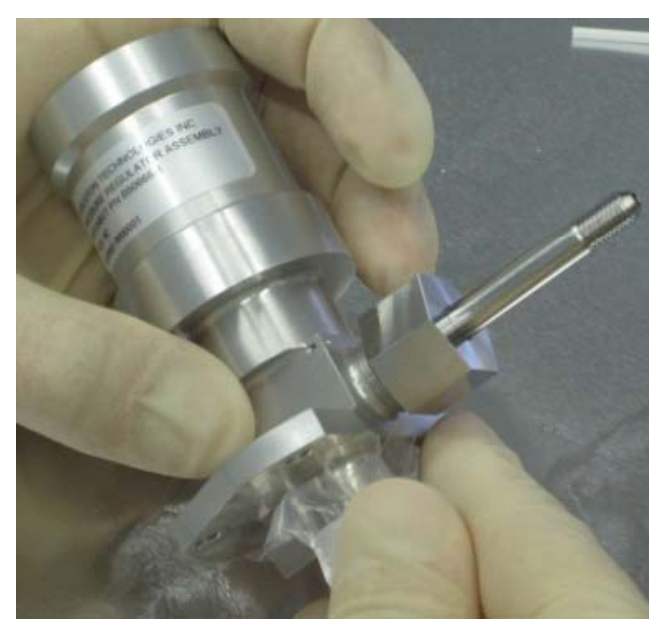

Carleton regulator unit under test by MSFC 


\section{High pressure regulator test ( 2 of 2 )}

\section{Status Summary}

A Cobham (formerly Carleton Technologies) regulator is chosen for this feasibility assessment due to the similarity of the heritage mission to the flow requirements of the RLLD spacecraft.

$\square$ Completing the test build up

- Complete final installation of plumbing system

- Conducted Test readiness review

$\square$ Test matrix for the ACS thruster will be composed of

- Tests to assess the internal leak rate during the lock-up condition.

- Tests with a simulated mission duty cycle at the actual total flow rate of propellants

- Slam start testing

Test is scheduled in September, 2010.

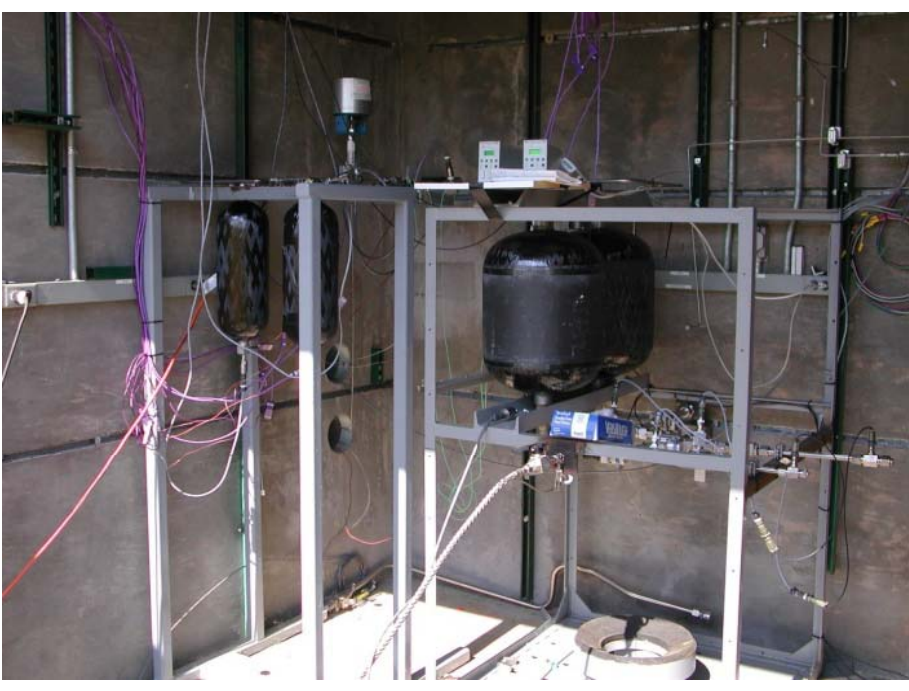

High pressure regulator test setup at MSFC 


\section{Background:}

\section{Task Overview}

$\square$ SRM is selected to provide high thruster for decelerating the lander prior to descent due to its high total impulse.

$\square$ Initial mission concept study requires SRM design parameters, such size, propellant, burn time, thrust profile, motor-to-motor performance variation, and structural interface.

\section{Work Status}

$\square$ Aerojet and ATK participated in the initial design study. STAR motor family in ATK catalog is used for motor sizing exercise.

$\square$ Thrust profiles and burn times due to temperature variation are predicted.

$\square$ Additional considerations, other motor sizes, thrust vector control for precision landing, are in work.

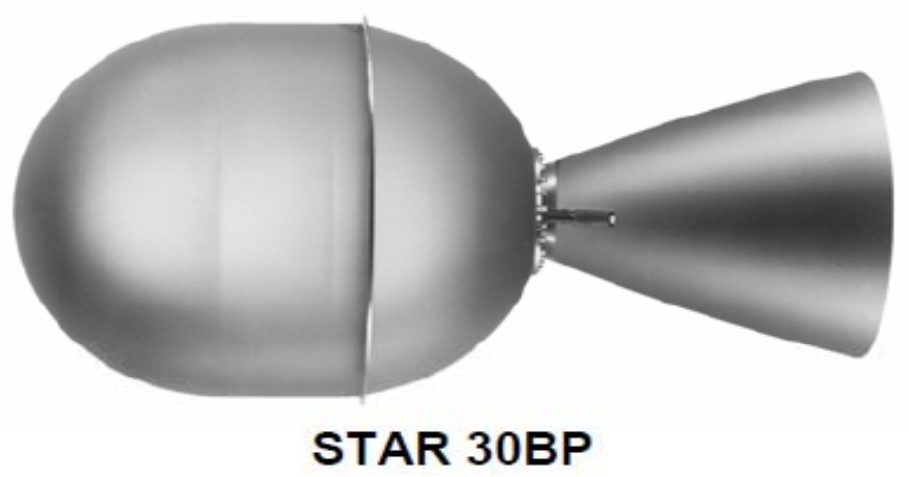

ATK STAR motor family used for initial sizing exercise 


\section{Conclusions}

$\square$ Making a significant progress in risk reduction activities for RLL propulsion development.

- Propulsion concept study shows trades between conventional spacecraft propulsion systems and high pressure systems.

- Up-to-date results on tests and initial concept design indicate high thrust-toweight thrusters suitable for RLL application

- On-going high pressure regulator test will assess the feasibility of using 10,000 psia helium pressurization system on NASA spacecrafts.

- SRM initial design has provided valuable data to the mission analysis team.

$\square$ Additional following work on the technology enhancements has been identified .

Most of activities will complete by 2010 .

$\square$ The risk reduction efforts have provided valuable data and information, especially in the area of high-pressure propulsion system for NASA spacecraft applications. 